\section{Lacrimal drainage surgery in patients with rare nasal diseases}

R Jain and GE Rose

\begin{abstract}
Aim To examine the results of open lacrimal drainage surgery in patients with rare nasal diseases.

Method A retrospective review of a group of patients with rare nasal disease who underwent open lacrimal surgery over a 15-year period at Moorfields Eye Hospital. Three main groups of disease were identified: (I) patients with treated mid-face tumours; (II) patients with prior major midfacial injury or surgery; and (III) patients with congenital nasal anomalies, including nasal aplasia. The more common systemic conditions of Wegener's granulomatosis and sarcoidosis were specifically excluded.

Results Eighty-six patients (43 men; 50\%) were identified with an age range between 1 and 82 years at the time of surgery. A total of 100 primary procedures were performed in 85 patients and symptomatic relief was achieved in $83 / 100(83 \%)$ eyes, with $18 / 100$ eyes $\mathbf{1 8 \%})$ requiring two or more lacrimal procedures. Lacrimal reconstructive surgery was considered impractical in two further patients. There were no intraoperative and few postoperative complications.

Conclusion With adequate experience, open lacrimal surgery appears to be a safe and effective procedure in the majority of patients with rare nasal diseases or major nasofacial anomalies.

Eye (2007) 21, 1361-1366; doi:10.1038/sj.eye.6702444; published online 1 September 2006
\end{abstract}

Keywords: nasal disease; lacrimal surgery; dacryocystorhinostomy

\section{Introduction}

In patients with rare conditions affecting the nasal passage, lacrimal drainage surgery poses a distinct surgical challenge and is largely unreported in the ophthalmic literature.

Lacrimal anatomy in these patients is often grossly distorted and the surgery requires an intimate knowledge of the available techniques. Diffuse scarring is often present (as part of an anomaly or due to previous surgery) and there may be destruction of the bone and paranasal sinuses by prior tumour or, in some cases, a complete lack of normal structures and spaces.

We report the surgical methods and symptomatic success in patients with rare nasal diseases, the nasal abnormalities being divided into three groups: (I) patients with prior treatment for complex tumours involving the nasal passages; (II) patients who had major midfacial trauma or extensive nasal surgery; and (III) patients with nasal dysplasia or aplasia, but excluding facial clefting syndromes, the experience of one author (GER) having already been reported. ${ }^{1}$

\section{Methods}

A retrospective case note review was undertaken for a group of patients undergoing open lacrimal drainage surgery at Moorfields Eye Hospital between 1988 and 2003. The modes of presentation, duration of disease, preoperative medical therapy, local radiotherapy, and surgery were recorded and the results, complications, and symptomatic control of lacrimal drainage surgery were examined. Patients with Wegener's granulomatosis or sarcoidosis, being relatively common in our experience, were specifically excluded. ${ }^{2,3}$

All surgery was performed by one surgeon (GER) and based on variations of the standard external dacryocystorhinostomy (DCR) technique: this consisted of a linear paranasal incision followed by complete release of the medial canthal tendon, a large rhinostomy and partial anterior ethmoidectomy, formation and
Lacrimal Service, Moorfields Eye Hospital, London, UK

Correspondence: GE Rose, Lacrimal Service, Moorfields Eye Hospital, 162 City Road, London EC1V 2PD UK

Tel: + 4402076552034

Fax: + 4402075662019

E-mail: geoff.rose@ moorfields.nhs.uk

Received: 10 October 2005 Accepted in revised form:

21 April 2006

Published online:

1 September 2006

Financial interest: none 
suture (with 6/0 Vicryl; Ethicon, Ltd) of both anterior and posterior mucosal flaps, and reconstruction of the medial canthal tendon, orbicularis, and skin. Silicone stents were used in most cases and removed in between 4 and 12 weeks after surgery.

Modifications of the standard DCR procedure were employed where necessary, such as canaliculo-DCR, DCR and fistulectomy (DCR + fistulectomy), DCR and retrograde canaliculostomy (retrograde-DCR), and DCR with primary placement of a canalicular bypass tube (open Jones tube). Nasal endoscopy and secondary placement of a canalicular bypass tube was undertaken where watering persisted after prior attempts at lacrimal reconstruction, or after loss of a primary Jones tube.

\section{Results}

Eighty-six patients (43 men; 50\%) presented between the ages of 1 and 82 years (mean 34; median 35) with lacrimal symptoms secondary to major nasal diseases. Primary surgery was performed in 100 systems (Table 1): 69 DCRs, four canaliculo-DCRs, six DCRs with fistulectomy, 12 retrograde-DCRs, and nine DCRs with open placement of Jones tubes. Median follow-up was 6 months (range 1-122 months) and 17 patients had further surgery with closed insertion of Jones tubes. At their final follow-up visit, $41 \%$ patients had no watering and $45 \%$ were much improved.

Complications of initial surgery included two suture granulomas and a case of fistula formation alongside a lateral rhinotomy scar in a patient after resection and irradiation of a malignant nasal tumour (Case 2; v.i.). Of the nine patients who received primary placement of a Jones tube ('open' Jones tube), six patients required later replacement - either to reposition a buried tube after primary placement (two cases) or for spontaneously lost tubes (four cases).

\section{Group I: Midfacial tumours}

The 21 patients (13 men; 61\%) in this group had a large variety of tumours - including recurrent nasal adenocarcinoma, nasal polyps, fibrosarcoma, melanoma, invasive basal-cell carcinoma, and extensive intranasal destructive lymphoma. Six patients had prior midfacial radiotherapy and eight patients underwent major midface resection before radiotherapy.

\section{Case report 1}

A 48-year-old lady with a history of massive midfacial lymphoma, treated 20 years previously with radiotherapy (Figure 1a and b), presented with right epiphora and underwent canaliculo-DCR that was initially successful. She developed bilateral epiphora 6 years later and underwent left primary and right redo canaliculo-DCR. Consequently, on the grossly scarred nasal space (Figure 1c), she continued to have some epiphora and underwent bilateral closed placement of Jones tubes with symptomatic control.

Case report 2

A 35-year-old Egyptian woman presented with left epiphora after surgery and radical radiotherapy for a

Table 1 Lacrimal surgery and outcome in 86 patients with complex nasal diseases

\begin{tabular}{|c|c|c|c|c|c|c|}
\hline $\begin{array}{l}\text { Group } \\
\text { number }\end{array}$ & $\begin{array}{l}\text { Type of nasal } \\
\text { disease }\end{array}$ & $\begin{array}{c}\text { Numbers of patients; } \\
\text { proportion of males } \\
\text { (\%) } \\
\text { Number of systems } \\
\text { operated }\end{array}$ & $\begin{array}{l}\text { Mean age at } \\
\text { presentation } \\
\text { (median; } \\
\text { range) }\end{array}$ & Primary procedures & $\begin{array}{l}\text { Secondary } \\
\text { procedures }\end{array}$ & $\begin{array}{c}\text { Final } \\
\text { symptomatic } \\
\text { control (number of } \\
\text { eyes }(\%))\end{array}$ \\
\hline I & $\begin{array}{l}\text { Prior mid-facial } \\
\text { tumours }\end{array}$ & $\begin{array}{c}21 ; 13 \text { males }(61 \%) \\
23 \text { systems }\end{array}$ & $\begin{array}{c}47 \text { years } \\
(45 ; 13-76)\end{array}$ & $\begin{array}{c}16 \text { Dacryocystorhinostomy } \\
2 \text { Canaliculo-DCR } \\
1 \text { DCR + fistulectomy } \\
4 \text { DCR + open LJT }\end{array}$ & 4 closed LJT & $\begin{array}{c}\text { Dry } 13 / 23(57 \%) \\
\text { Improved } 6 / 23 \\
(26 \%) \\
\text { Unchanged } 4 / 23 \\
(17 \%)\end{array}$ \\
\hline II & $\begin{array}{l}\text { Nasal trauma or } \\
\text { surgery }\end{array}$ & $\begin{array}{c}\text { 43; } 21 \text { males }(49 \%) \\
46 \text { systems }\end{array}$ & $\begin{array}{l}39 \text { years } \\
(39 ; 8-82)\end{array}$ & $\begin{array}{c}37 \text { Dacryocystorhinostomy } \\
2 \text { Canaliculo-DCR } \\
3 \text { Retrograde-DCR } \\
4 \text { DCR + open LJT }\end{array}$ & 9 closed LJT & $\begin{array}{c}\text { Dry } 18 / 46(39 \%) \\
\text { Improved } 23 / 46 \\
(50 \%) \\
\text { Unchanged } 4 / 46 \\
(11 \%)\end{array}$ \\
\hline III & $\begin{array}{l}\text { Nasal dysplasia } \\
\text { or aplasia }\end{array}$ & $\begin{array}{l}22 ; 9 \text { males }(40 \%) \\
31 \text { systems }\end{array}$ & $\begin{array}{l}15 \text { years } \\
(8 ; 1-51)\end{array}$ & $\begin{array}{c}16 \text { Dacryocystorhinostomy } \\
9 \text { Retrograde-DCR } \\
5 \text { DCR + fistulectomy } 5 \\
1 \text { DCR + open LJT }\end{array}$ & $\begin{array}{l}4 \text { closed LJT } \\
1 \text { redo-DCR }\end{array}$ & $\begin{array}{c}\text { Dry } 10 / 31(32 \%) \\
\text { Improved } 16 / 31 \\
(52 \%) \\
\text { Unchanged } 5 / 31 \\
(16 \%)\end{array}$ \\
\hline
\end{tabular}

'DCR' denotes dacryocystorhinostomy; 'Retrograde-DCR' denotes DCR with retrograde canaliculostomy; 'open LJT' denotes open placement of Lester Jones tube; 'closed LJT' denotes closed placement of Lester Jones tube. 

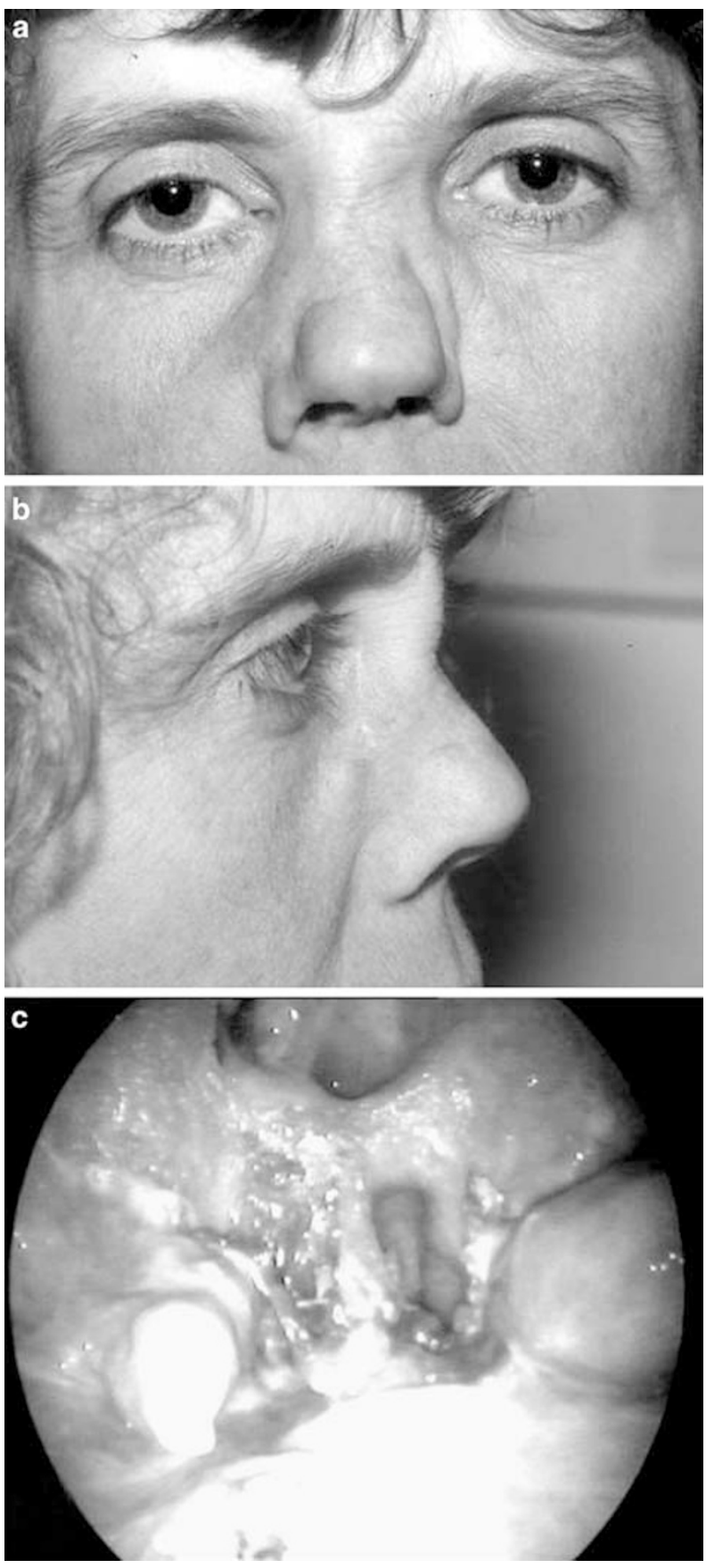

Figure 1 (Case 1) A patient presenting with bilateral epiphora, 20 years after radiotherapy for midline nasal lymphoma. There was marked distortion of her nose (a), collapse of the nasal bridge (b) and nasal endoscopy (c) demonstrated complete loss of the septum and turbinates, with gross squamous metaplasia and crusting of the nasal walls and skull base.

malignant naso-ethmoidal tumour. She underwent left DCR with intubation and excision of a lacrimal sac fistula; a thickened, chronically inflamed lacrimal sac and nasal mucosa was evident at operation and mucosal anastomosis was difficult. Ischaemic necrosis of an area

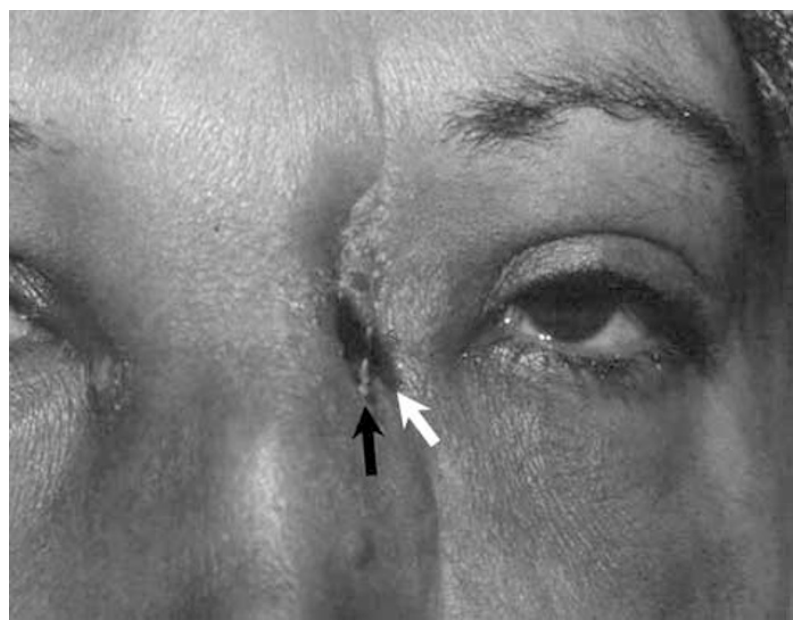

Figure 2 (Case 2) Ischaemic necrosis of a narrow bridge of tissue between the DCR incision (black arrow) and lateral rhinotomy scar (white arrow). Tissue breakdown occurred about 2 weeks after lacrimal surgery, with necrosis of skin that had previously received high-dose radiotherapy after resection of midfacial malignancy.

of irradiated skin, between the DCR incision and the lateral rhinotomy scar, occurred over about 2 weeks after surgery and was later repaired (Figure 2).

\section{Group II: Major nasal trauma or surgery}

Forty-three patients (21 men: 49\%) underwent surgery for lacrimal drainage obstruction arising from major nasal injury or following complex nasal surgery; one further patient was untreatable (Case $3 ;$ v.i.). The trauma included midfacial fractures, orbital fractures, and rhinoplasty or major sinus surgery for chronic nasal disease. Twenty-three patients (54\%) had previous major nasal, maxillary, ethmoidal, or orbital surgery that affected some part of the lacrimal drainage system.

\section{Case report 3}

A 65-year-old man underwent multiple excisions of basal cell carcinoma involving his nose and paranasal area (Figure 3a). Watering of his left eye, with distortion of the inner canthus, was due to absence of the lacrimal sac and nasolacrimal duct. The patient controlled his symptoms by placing a cotton wool ball within his nasal prosthesis and drawing excess fluid from the tear lake by rolling a pledget into the left inner canthus (Figure 3b). There was no realistic benefit from lacrimal surgery and this patient was, therefore, deemed untreatable.

\section{Case report 4}

Having had a road traffic accident 3 years before - with significant left lower lid injury and nasal fractures - a 28year-old man presented with left epiphora (Figure 4); he 

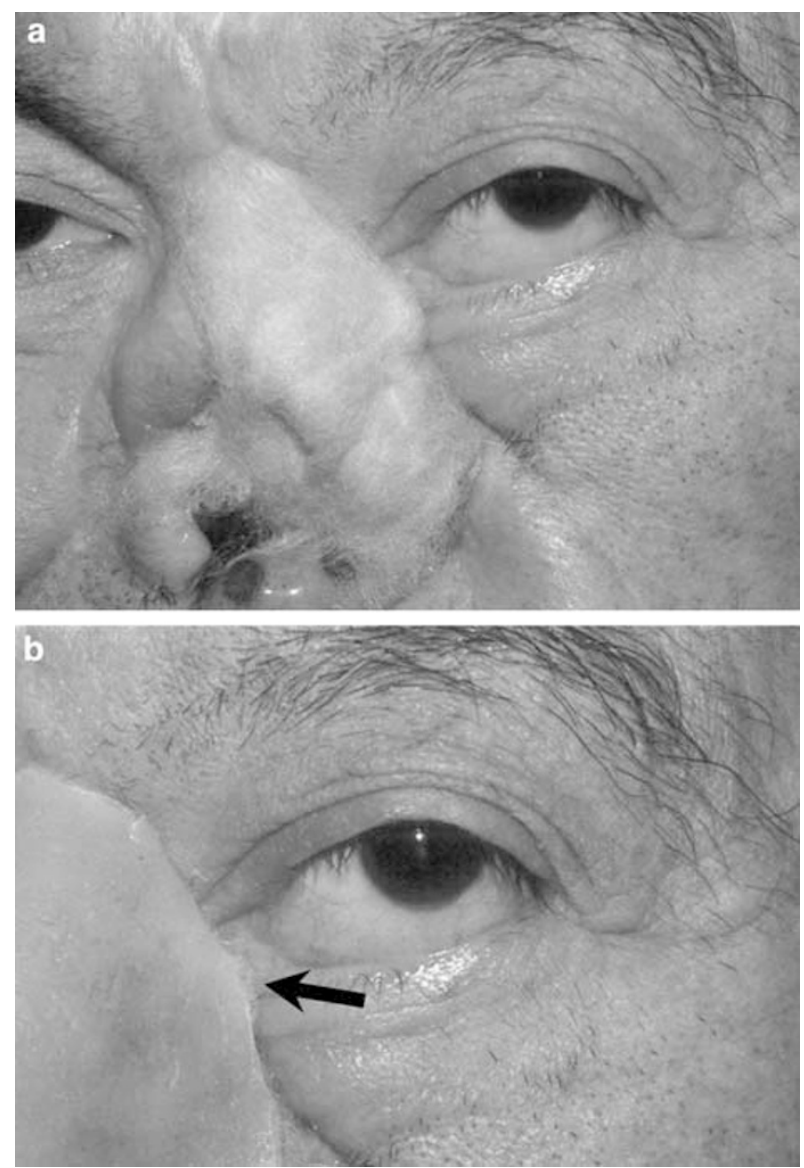

Figure 3 (Case 3) (a) Nasal destruction and loss of tissues from the upper lip and maxilla after multiple operations for recurrent basal cell carcinoma. The patient placed a cotton-wool ball under his hollow nasal prosthesis (b), using a tiny 'wick' of cotton wool (arrow) to draw tears away from his left inner canthus; the patient would replace the cotton wool several times daily and thereby control troublesome epiphora.

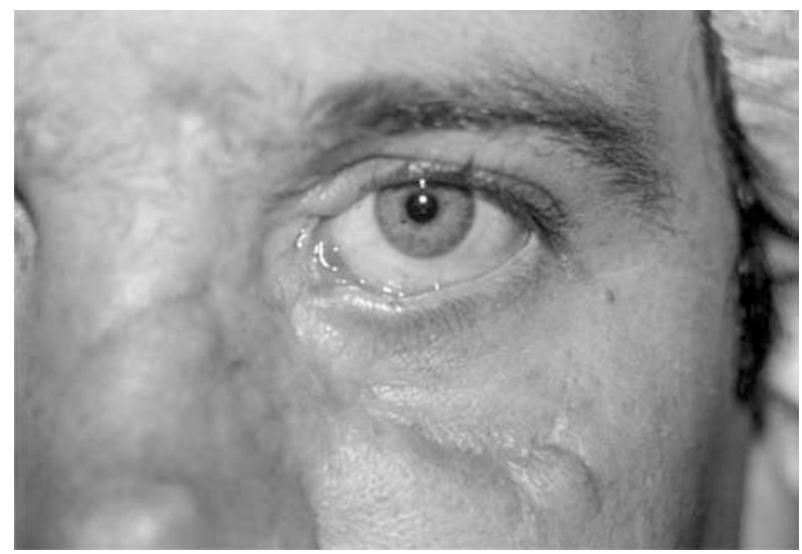

Figure 4 (Case 4) Scarring of the eyebrows, eyelids, and nasal bridge following repair of major midfacial and orbital fractures owing to a road traffic accident; marked distortion of the left inner canthus and bicanalicular transaction is particularly evident. had undergone two previous repairs to the nose and left lower lid with no improvement in symptoms. When seen, he had extensive scarring across his brow, nose, and left lower lid and both limbs of the left medial canthal tendon appeared detached. He underwent a left DCR, repair of $\mathrm{MCT}$, and excision of scar tissue. He subsequently underwent a Lee medial canthoplasty and his symptoms have resolved.

\section{Group III: Nasal dysplasia}

Twenty-two patients (nine men; 41\%) underwent surgery for epiphora secondary to congenital nasal malformations, some of the patients having syndromes such as Klein-Waardenburg, Saethre-Chotzen, Fraser's, or ectrodactyly, ectodermal dysplasia, and clefting (EEC). The malformations included canalicular or lacrimal sac agenesis, unilateral complete agenesis of the lacrimal system, or nasolacrimal duct abnormalities such as congenital fistulae, cysts, and 'blind' ducts. One patient was considered untreatable (Case 6).

\section{Case report 5}

An 18-year-old girl with right hemifacial microsomia (Figure 5a) had persistent ipsilateral epiphora, despite a previous DCR aged 4 years. An expressible right lacrimal sac mucocoele was present, but with no discernable right nasal space and a limited left nasal space (Figure $5 b$ ). She underwent a right revisional DCR, in which the rhinostomy was extended to the left nasal space and the tubes were passed through the left nares. The silicone intubation was removed at a month after surgery, with resolution of symptoms.

\section{Case report 6}

A 7-year-old boy with total nasal atresia and maxillary hypoplasia underwent fashioning of a nasal passage shortly after birth (Figure 6a), this requiring frequent stenting to maintain patency. The presence of bilateral epiphora in the absence of a true nasal space was considered untreatable (Figure 6b).

\section{Discussion}

The management of lacrimal obstruction in patients with complex nasal abnormalities, either congenital or acquired, is difficult and these patients manifest a wide variety of abnormalities.

In patients with nasal tumours, lacrimal drainage obstruction may arise from direct mucosal invasion ${ }^{4}$ and tumours of the nasal epithelium may infiltrate the lacrimal system without destruction of periorbital bone or nasal cartilage. Lacrimal duct obstruction as a result of previously undiagnosed tumour has been reported in up 

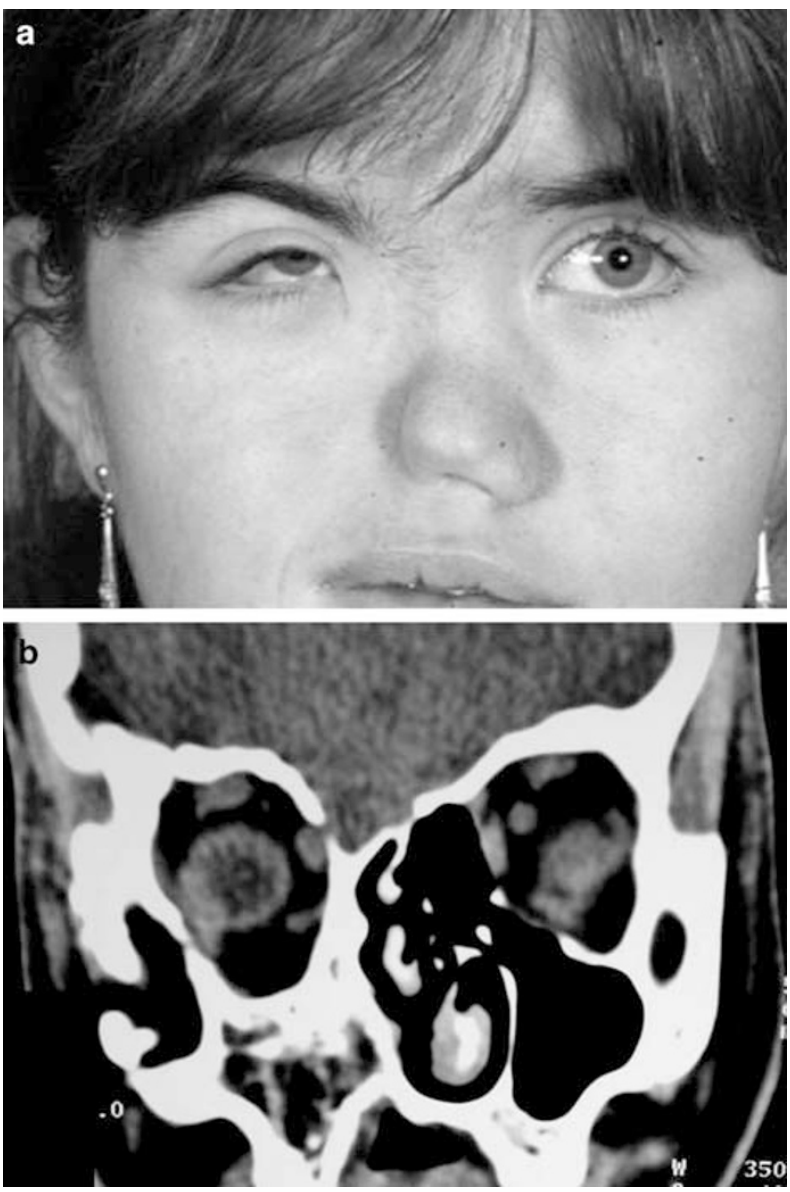

Figure 5 (Case 5) (a) Right lacrimal obstruction associated with hemifacial microsomia. Coronal CT (b) shows a low skull base on the right side, with absent right ethmoids and turbinates, and a highly distorted ipsilateral maxilla. There is no evidence of a nasal septum or right nasal space, there being only distorted left intranasal structures within the air cavity that is present.

to $5 \%$ of patients undergoing $\mathrm{DCR},{ }^{5}$ but this is almost certainly an overestimate and may be owing to referral bias.

Craniofacial trauma involving the midfacial structures can result in troublesome epiphora, with a reported incidence of $47 \%$ following these fractures; lacrimal reconstruction, performed 6 months after primary surgery and using a similar technique to this study, achieved symptomatic control in most cases. ${ }^{6}$ It has been suggested that lacrimal surgery should be deferred for at least 6 months after midfacial surgery. ${ }^{7}$

Nasal dysplasia or aplasia is commonly associated with nasolacrimal duct obstruction, ${ }^{8}$ and may require endoscopic removal of abnormal nasal tissue as well as the external DCR. ${ }^{9}$ Endoscopic resection of abnormal mucosa from the lacrimal system has also been described..$^{10}$ Jones tubes have been used with success in some patients, particularly with partial nasal aplasia. ${ }^{11}$
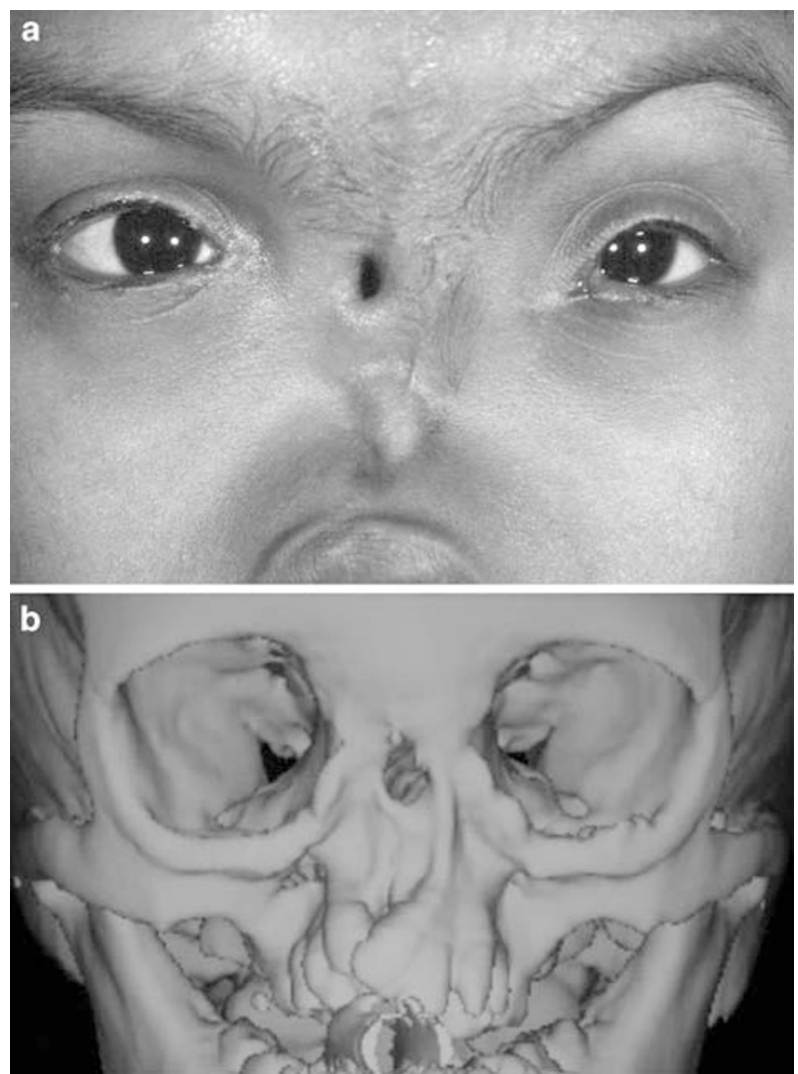

Figure 6 (Case 6) (a) Surgically created 'nasal' passage in a child with complete nasal aplasia and marked maxillary hypoplasia. Three-dimensional CT (b) demonstrates the gross midfacial anomaly.

The complication rate in this series of complex cases was relatively low. The one significant complication, ischaemic necrosis of irradiated skin in a narrow bridge between the DCR incision and the previous rhinotomy scar (Figure 2), could probably have been avoided by placing the DCR incision either in, or at a much greater distance from, the lateral rhinotomy scar. Although there have been no comparative studies, a single case of wound necrosis after open lacrimal surgery has been described in a patient with Wegener's granulomatosis. ${ }^{11}$

\section{References}

1 Hicks C, Pitts J, Rose GE. Lacrimal surgery in patients with congenital cranial or facial anomalies. Eye 1994; 8: 583-591.

2 Kwan AS, Rose GE. Lacrimal drainage surgery in Wegener's granulomatosis. Br J Ophthalmol 2000; 84: 329-331.

3 Chapman KL, Bartley GB, Garrity JA, Gonnering RS Lacrimal bypass surgery in patients with sarcoidoisis. Am J Ophthalmol 1999; 127: 443-446.

4 Hatano Y, Terashi H, Kurata S, Asada Y, Shibuya H, Tanaka A. Invasion of the lacrimal system by basal cell carcinoma. Dermatol Surg 1999; 25(10): 823-826. 
5 Anderson NG, Wojno TH, Grossniklaus HE. Clinicopathologic findings from lacrimal sac biopsy specimens obtained during dacryocystorhinostomy. Ophthalmic Plast Reconstr Surg 2003; 19: 173-176.

6 Becelli R, Renzi G, Mannino G, Cerulli G, Iannetti G. Posttraumatic obstruction of lacrimal pathways: a retrospective analysis of 58 consecutive naso-orbitoethmoid fractures. J Craniofac Surg 2004; 15: 29-33.

7 Adenis JP, Mathon C, Lebraud P, Franco JL. Dacryocystorhinostomy. Retrospective study of 165 cases. Indications. Technic. Results. Comparative study of 25 cases of injury with 165 cases including all etiologies. $J \mathrm{Fr}$ Ophtalmol 1987; 10: 323-329.
8 Lueder GT. Endoscopic treatment of intranasal abnormalities associated with nasolacrimal duct obstruction. J AAPOS 2004; 8: 128-132.

9 Wong JF, Woog JJ, Cunningham MJ, Rubin PA, Curtin HD, Carter BL. A multidisciplinary approach to atypical lacrimal obstruction in childhood. Ophthalmic Plast Reconstr Surg 1999; 15: 293-298.

10 Tsur H, Winckler E, Orenstein A, Rosen N. Nasal reconstruction combined with dacryocystorhinostomy in a patient with absence of half of the nose. Ophthalmic Surg Lasers 1997; 28: 680-682.

11 Jordan DR, Miller D, Anderson RL. Wound necrosis following dacryocystorhinostomy in patients with Wegener's granulomatosis. Ophthalmic Surg 1987; 18: 800-803. 